\title{
Retracted Article: Effect of Short Term Use of Repetitive Transcranial Stimulation as an Adjuvant Therapy for Bell's Palsy
}

\author{
Samira Oshaghi ${ }^{1}$, Keyvan Ghadimi $^{2,{ }^{*},}$, Ahmad Rezaeian ${ }^{3}$ and Zeinabsadat Dokhanchi ${ }^{3}$ \\ ${ }^{1}$ Physical Medicine and Rehabilitation, School of Medicine, Isfahan University of Medical Sciences, Isfahan, Iran \\ ${ }^{2}$ School of Medicine, Isfahan University of Medical Sciences, Isfahan, Iran \\ ${ }^{3}$ Department of Otorhinolaryngology, School of Medicine, Isfahan University of Medical Sciences, Isfahan, Iran \\ Corresponding author: School of Medicine, Isfahan University of Medical Sciences, Isfahan, Iran. Email: keyvanghadimi@yahoo.com
}

Received 2018 June 30; Revised 2018 July 23; Accepted 2018 August 29.

\section{Abstract}

Background: There is limited therapy for management of Bell' palsy. However, none of the tre nent . adalities are effective, thus, the aim of this study was to evaluate the effect of repetitive transcranial stimulation(rTMS), an a. 'vant herapy, for management of Bell's palsy.

Methods: In this randomized controlled trial, 46 patients with unilateral Bell's $\mathrm{F}$ were ent "ed and were divided to two parallel groups an intervention and control groups. The intervention group was under $\mathrm{t}$ atm two weeks and, continued with physical therapy/daily and rTMS/five sessions a we 000 stimuli, $120 \%$ motor threshold) for two weeks and the control group was under treatment with oral prednisc'one $1 \mathrm{mg} / \mathrm{kg} / \mathrm{c}$ y for two weeks and continued with physical therapy/daily for two weeks. The outcome was measured with the facl, disability il lex (FDI), House-Brackmann (H-B) scale and World Health Organization quality of life (WHOQOL)-BREF questionn re a aseline, and two and four weeks after therapy.

Results: The physical and social functions of FDI and WHOQOL-BRI questi vaire in the intervention group were significantly higher than the control group after four weeks. Also, H-B gradi the ention group was better than the control group after four weeks.

Conclusions: The rTMS as adjuvant therapy may be an ive, n-iny sive, and safe method for management of Bell's palsy.

Keywords: Bell's Palsy, Repetitive Transcranial Stip num, רorovement, Adjuvant Therapy

\section{Background}

Facial paralysis mostly slve the facial nerve and can effect quality of life. This $n$ ve in udes sensory, motor and parasympathet $\mathrm{MD}$. $s$ an amage to this nerve can effect sensor-moto a a pa asympathetic conditions. The symptor of $\mathrm{f}_{c}$ ial pa sis includes incomplete eye

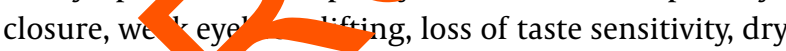
eyes, drooping ff mouth corner, ear pain, and hyperacusis. Facial paraly is divided to two categories, including central and peripheral. In central facial paralysis, the disorder is above the facial nucleus while the disorder in facial nerve and nucleus is in peripheral facial paralysis. Bell's palsy is an idiopathic subtype of the peripheral facial nerve $(1,2)$. The most common hypotheses about the etiology of Bell's palsy are rheumatic, viral, immunological, and herpes infection. The incidence of Bell's palsy is 15 to 40 cases per 100000 of the general population and is prevalent in females and middle age groups $(3,4)$. In adults, ag- ing, pregnancy, and diabetes are significant risk factors of Bell's palsy and getting colds is a risk factor in children (5, 6). High dosage of steroids is used as a bolus dose in onset and tapered off over the next one to two weeks, also physiotherapy is done as complementary therapy, including galvanism, massage, and facial exercises. Also, surgical management is suggested for damage to the nerve and muscle $(7,8)$. The use of electrical stimulation for Bell's palsy is another therapeutic approach that has been previously reported (9). Considering that various therapeutic methods have been used with different results for the treatment of Bell's palsy, and in particular, no standard treatment for this disease has been provided, for the first time, singlepulse transcranial stimulation was used as a therapeutic tool in 1985(10). Repetitive transcranial stimulation (rTMS) is a safe and non-invasive method of brain stimulation, in which the magnetic field induces an electric field in the cerebral cortex, and this electric field causes the depolarization of neurons (11). 


\section{Objectives}

Therefore, in the current study, the researchers assessed which rTMS could be useful in the treatment of Bell's palsy. The aim of this study was evaluation of the effect of rTMS on the treatment of Bell's palsy.

\section{Methods}

\subsection{Study Design}

In this randomized, clinical trial, which was approved in Isfahan University of Medical Sciences (No.: 395039) and was registered at the Iranian Registry of Clinical Trial (IRCT2017100312782N20), 59 patients with unilateral Bell's palsy were referred to the physical medicine and rehabilitation clinics in 2015 to 2017. This research selected 46 patients ( 21 males and 25 females) with the mean age of $46.78 \pm 14.14$ years, according to the inclusion and exclusion criteria. All patients were diagnosed according to clinical findings, physical examination, electromyography, and electroneurography. Inclusion criteria included patients with unilateral Bell' palsy, aged over 18 years old, and informed consent to participate in the study. Also, patients with a history of botulinum toxin injection in the last six months, uncontrolled diabetes, severe hyp cension, liver and kidney disease, peptic ulcer, his ary of to cment for facial nerve palsy or previous histo $y$ of fa nerve paralysis or recurrence of disease, $c_{\text {Mer net }}{ }^{1 /} \mathrm{g}$ ical disorders, such as seizure, traumatic rain i jury or stroke, pregnancy, middle ear disea anc ict ry of facial muscle surgery, were exclude $\mathrm{Pa}$ e $s$ who had severe complications or were not ollow d $u r$, were excluded from the study. The patic + we randomly allocated with the random allocation soft re to wo parallel groups as intervention and $\mathrm{co}$ (ro rou $\mathrm{rou}_{\mathrm{b}}$ The intervention group was treated ..ith o v red isolone $1 \mathrm{mg} / \mathrm{kg} /$ day for two weeks, a afte trea , the treatment was continued using torcis sessions in two weeks, he control group was treated with oral prednisolone $1 \mathrm{mg}, \mathrm{g} /$ day for two weeks, and after the end of oral therapy, the exercise physiotherapy was continued for two weeks (six seasons) on a daily basis. The rTMS was done with 1000 stimuli, and $120 \%$ intensity of resting motor threshold (RMT) with eight coils and the device was the Magstim Rapid stimulator (Magstim Company, Dyfed, UK). The site for recording stimulation was prefrontal. The frequency of stimulations was $1 \mathrm{~Hz}$ rTMS (1 train, 1000 Stimuli) and $10 \mathrm{~Hz}$ (20 trains, 50 stimuli per train, the intertrain interval of 25 seconds).

\subsection{Assessments}

The outcomes were measured with facial disability index (FDI), House-Brackmann (H-B) scale, and the World Health Organization quality of life (WHOQOL)-BREF questionnaire. The FDI consists of 10 items in two areas: physical and social/well-being functions. The physical and social function of FDI consists of five different questions about facial muscles function (12). The H-B scale is a grading for measurement of facial nerve dysfunction, and this scale consists of six grades as normal (1), $\mathrm{m}$, (2) moderate (3), moderately severe (4), severe (3, and to par lysis (6) (13). The WHOQOL-BREF questionnaire no 26 items that assess the quality of life of $p$ crents $\mathrm{h}$ four areas of physical health, psychological, sc ial rel ionships, and the environment (14). I eas les recorded at baseline, two and four weel ser ti tment and the doctor, who recorded these les wa aware of the implementation of the $\mathrm{dv}$. Also the demographic information of patients $w$ rec and on a checklist, and included age, gender, dura $\quad$ of Bell's palsy, involved side, and complications.

\subsection{5 tistics}

The sample size was calculated according to confidence level of $95 \%$ and the power detection was $80 \%$. Also, the means were 0.50 and 0.82 (15). Therefore, the sample size was 23 for each group. All data were analyzed with the SPSS software. Chi-square, independent $t$-test, and Mann Whitney were used to compare the two groups, and the repeated measure analysis of variance (ANOVA) was used to compare variables at different times. Also, data were shown as number (along with percentage) and mean \pm SD. The P value $<0.05$ was considered a significant threshold.

\section{Results}

In this study, 46 patients participated in the intervention group (12 males and 11 females, mean age $47.17 \pm$ 13.65 years) and the control group (nine males and fourteen females), also there were no significant differences between two group regarding age $(\mathrm{P}=0.68)$, gender $(\mathrm{P}=$ 0.37 ), involved site (0.13) and duration of disease (0.53) (demographic information of patients is summarized in Table 1). The physical and social functions of FDI, H-B grading, and WHOQOL-BREF questionnaire were recorded at the baseline, and after two and four weeks. At baseline and after two weeks, these scales were insignificant in 


\begin{tabular}{|c|c|c|c|}
\hline Characteristic & $\begin{array}{l}\text { Intervention } \\
\text { Group }\end{array}$ & Control Group & PValue \\
\hline Number & 23 & 23 & - \\
\hline Gender & & & $0.37^{*}$ \\
\hline Male & $12(52.2)$ & $9(39.1)$ & \\
\hline Female & $11(47.8)$ & $14(60.9)$ & \\
\hline Age (y) & $47.17 \pm 13.65$ & $46.39 \pm 14.92$ & $0.68^{* *}$ \\
\hline Involved side & & & $0.13^{*}$ \\
\hline Right & $15(65.2)$ & $10(43.5)$ & \\
\hline Left & $8(34.8)$ & $13(56.5)$ & \\
\hline $\begin{array}{l}\text { Duration of } \\
\text { disease }(d)\end{array}$ & $19.65 \pm 10.23$ & $19.95 \pm 12.37$ & $0.53^{* *}$ \\
\hline
\end{tabular}

${ }^{a}$ Values are expressed as No. (\%) or mean \pm SD.

$\mathrm{b}^{*}$ Chi squire test, ${ }^{* *}$ independent $t$-test.

both groups yet after four weeks, physical and social functions of FDI and WHOQOL-BREF questionnaire in the intervention group were significantly higher than the control group (P value was 0.04 for physical function, 0.03 for social function, and 0.02 for the WHOQOL-BREF questionnaire). Also, there was a significant difference between both groups, according to $\mathrm{H}-\mathrm{B}$ grading $(\mathrm{P}=0.03)$ (Other data are summarized in Table 2). Also, repeated mesure ANOVA showed that changing of physical and social func tions of FDI and WHOQOL-BREF scales were significant different times $(\mathrm{P}<0.001$, for all). None of the $\mathrm{P}$, ent had severe complications. One patient of the int men group and two patients of the control group w excly dea from the study.

\section{Discussion}

According to the current re Its, $\mathrm{t}$ addition of rTMS to the treatment of Bely pa ha large effect because the scores, such nhys and ocial functions of FDI and WHOQOL-BP que ion after the four weeks in the interventio gro bigher than the control group. Also, three pat hts in the intervention group had normal function after fou yeeks. Therefore, the addition of rTMS can be affected by social and physical functions, grading of Bell's palsy, physical health, psychological, social relationships, and the environment in patients with Bell's palsy. In a pilot study by George et al. (16) in 1995, that evaluated the effect of rTMS for five patients with depression, it was shown that depression scores were improved in patients and mood and depression completely remitted. Also, the authors suggested daily left prefrontal rTMS for management of depression as a safe and well-tolerated procedure.
In the study performed by Forogh et al. (17), who investigated rTMS effects on the postural balance problems in 26 stroke patients, it was concluded that adjuvant of rTMS could improve the effect on static postural stability, coordination, falling risk, muscle strength, and recovery in the stroke patients. Also, Jhanwar et al. (18) evaluated the effect of rTMS as an adjuvant therapy for 21 patients with resistant depression and only four patients had headache as a side effect, yet there was no serious adverse effect. Also, the authors suggested rTMS as an augmenting thorapy in resistant depression. In another study that es olor 4 the effect of cerebellar rTMS on cerebellothan noc ical athways in ten healthy subjects, the motor thre ola and stimulation were $120 \%$ and 1000 stimu , resperti $1 y$, and the frequencies were 1 and $10 \mathrm{~Hz}$, th ' $\mathrm{l}$ lo freq ency $(1 \mathrm{~Hz})$ of rTMS increased short intraco cal hibituon (SICI) and high frequency had no effect on a rnat.on of SICI (19). Also, the therapeutic effects $\mathrm{C}$ TMS in neurological patients was observed, $1 m$ ish the se of rTMS increased the speed of movemer ar an cased tremor in resting mode in Parkinson's di ase and reduced spasticity in patients with Pa inson's dis se and multiple sclerosis (20-22). In a rand Ant clinical trial study by Tuncay (9), who evaluated e effec $f$ electrical stimulation as adjuvant therapy in $\mathrm{O}_{\mathrm{P}}$. Its with Bell's palsy and outcomes measured with $\mathrm{H}$ scale and FDI scores, it was concluded that addition of ectronic stimulation (3 weeks/daily) after onset of treatment improved functional facial movements and outcome measurements. In a review article by Galhardoni et al. (23), it was demonetarized that rTMS has a high effect on the management of chronic pain. Also, the low frequency of rTMS is an effective method for patients with aphasia after stroke (24).

The current research was the first to study the effect of rTMS as adjuvant therapy in Bell's palsy, and showed that rTMS has greater effect on the improvement of functions in this disease. Also, this study suggested rTMS as an effective, safe, and non-invasive method for improvement of Bell's palsy and the limitation of this study was low sample size, and short follow up. It is recommended to perform future studies in this regard with a larger sample size and extended follow up.

\section{Footnote}

Financial Disclosure: This study approved in Isfahan University of Medical Sciences and IRCT. 
Table 2. The Physical and Social Functions of FDI, House-Brackmann (H-B) Scale and WHOQOL-BREF Questionnaire in Both Groups at Baseline, and Two and Four Weeks After Treatment $^{\mathrm{a}}$

\begin{tabular}{|c|c|c|c|}
\hline Variable & Intervention Group & Control Group & P Value \\
\hline \multicolumn{4}{|l|}{ Physical function of FDI } \\
\hline Baseline & $46.26 \pm 13.35$ & $47.65 \pm 11.30$ & 0.72 \\
\hline After 2 weeks & $64.34 \pm 12.29$ & $66.27 \pm 11.58$ & 0.65 \\
\hline After 4 weeks & $77.45 \pm 12.50$ & $69.80 \pm 11.62$ & 0.04 \\
\hline \multicolumn{4}{|l|}{ Social function of FDI } \\
\hline Baseline & $49.08 \pm 12.80$ & $49.39 \pm 11.97$ & 0.89 \\
\hline After 2 weeks & $67.56 \pm 13.96$ & & 0.88 \\
\hline After 4 weeks & $80.18 \pm 13.88$ & & 0.03 \\
\hline House-Brackmann grading & & & 0.41 \\
\hline \multicolumn{4}{|l|}{ Baseline } \\
\hline Mild & $4(17.4)$ & & \\
\hline Moderate & $9(39.1)$ & 9) & \\
\hline Moderately severe & $7(30.4)$ & $6(26.1)$ & \\
\hline Severe & & $1(4.3)$ & \\
\hline After 2 weeks & & & 0.59 \\
\hline Mild & 13 & $13(59.1)$ & \\
\hline Moderate & $7(30.4)$ & $8(36.4)$ & \\
\hline Moderately severe & $3(13)$ & $1(4.5)$ & \\
\hline After 4 weeks & & & 0.03 \\
\hline Normal & $3(13.6)$ & $0(0)$ & \\
\hline Mild & $18(81.8)$ & $15(71.4)$ & \\
\hline Moderate & $1(4.5)$ & $6(28.6)$ & \\
\hline \multicolumn{4}{|c|}{ WHOQOL-BREF questionnaire, total score } \\
\hline Baseline & $58.26 \pm 14.31$ & $57.43 \pm 11.85$ & 0.83 \\
\hline After 2 weeks & $68.17 \pm 12.58$ & $66.50 \pm 11.58$ & 0.70 \\
\hline After 4 weeks & $76.81 \pm 12.59$ & $69.52 \pm 10.60$ & 0.02 \\
\hline
\end{tabular}

Abbreviations: FDI: facial disabilit dex, $\mathrm{W}$ QOL: World Health Organization quality of life.

${ }^{a}$ Values are expressed as No. (\%) or m \pm SD.

\section{Referenc}

1. Stew Will: Modern management of facial palsy: A review of ent literature. Br J Gen Pract. 2013;63(607):109-10. doi: 10.3399/bjg, 2X663262. [PubMed: 23561689]. [PubMed Central: PMC3553607].

2. Zhao Y, Feng G, Gao Z. Advances in diagnosis and non surgical treatment of Bell's palsy. J Otol. 2015;10(1):7-12. doi: 10.1016/j.joto.2015.02.003. [PubMed: 29937775]. [PubMed Central: PMC6002555].

3. Malik N. Facial nerve and motor disturbances of the face and jaws. Text book of oral and maxillofacial surgery. 2nd ed ed. New Delhi: Jaypee Brothers Medical Publishers; 2008. p. 719-21.

4. Rajapur A, Mitra N, Prakash VJ, Rah SA, Thumar S. Prosthodontic Rehabilitation of Patients with Bell's Palsy: Our Experience. J Int Oral Health. 2015;7(Suppl 2):77-81. [PubMed: 26668488]. [PubMed Central: PMC4672843].
5. Monini S, Lazzarino AI, Iacolucci C, Buffoni A, Barbara M. Epidemiology of Bell's palsy in an Italian Health District: Incidence and casecontrol study. Acta Otorhinolaryngol Ital. 2010;30(4):198. [PubMed: 21253285]. [PubMed Central: PMC3008145].

6. Tsai HS, Chang LY, Lu CY, Lee PI, Chen JM, Lee CY, et al. Epidemiology and treatment of Bell's palsy in children in northern Taiwan. J Microbiol Immunol Infect. 2009;42(4):351-6. [PubMed: 19949760].

7. Numthavaj P, Thakkinstian A, Dejthevaporn C, Attia J. Corticosteroid and antiviral therapy for Bell's palsy: A network meta-analysis. BMC Neurol. 2011;11:1. doi: 10.1186/1471-2377-11-1. [PubMed: 21208452] [PubMed Central: PMC3025847].

8. Terzis JK, Konofaos P. Nerve transfers in facial palsy. Facial Plast Surg. 2008;24(2):177-93. doi: 10.1055/s-2008-1075833. [PubMed: 18470829].

9. Tuncay F, Borman P, Taser B, Unlu I, Samim E. Role of electrical stimulation added to conventional therapy in patients with idio- 
pathic facial (Bell) palsy. Am J Phys Med Rehabil. 2015;94(3):222-8. doi: 10.1097/PHM.0000000000000171. [PubMed: 25171666].

10. Corthout E, Barker AT, Cowey A. Transcranial magnetic stimulation Which part of the current waveform causes the stimulation? Exp Brain Res. 2001;141(1):128-32. doi: 10.1007/s002210100860. [PubMed: 11685417].

11. Neville IS, Hayashi CY, El Hajj SA, Zaninotto AL, Sabino JP, Sousa LM Jr, et al. Repetitive Transcranial Magnetic Stimulation (rTMS) for the cognitive rehabilitation of traumatic brain injury (TBI) victims: Study protocol for a randomized controlled trial. Trials. 2015;16:440. doi: 10.1186/s13063-015-0944-2. [PubMed: 26438108]. [PubMed Central: PMC4594992].

12. VanSwearingen JM, Brach JS. The Facial Disability Index: Reliability and validity of a disability assessment instrument for disorders of the facial neuromuscular system. Phys Ther. 1996;76(12):1288-98. discussion 1298-300. [PubMed: 8959998].

13. House JW, Brackmann DE. Facial nerve grading system. Otolaryngol Head Neck Surg. 1985;93(2):146-7. doi: 10.1177/019459988509300202. [PubMed: 3921901].

14. World Health Organization. WHOQOL-BREF: Introduction, administration, scoring and generic version of the assessment: Field trial version, December 1996. Geneva: World Health Organization; 1996.

15. Chang WH, Bang OY, Shin YI, Lee A, Pascual-Leone A, Kim YH. BDNF polymorphism and differential rTMS effects on motor recovery of stroke patients. Brain Stimul. 2014;7(4):553-8. doi: 10.1016/j.brs.2014.03.008. [PubMed: 24767962].

16. George MS, Wassermann EM, Williams WA, Callahan A, Ketter TA, Basser $P$, et al. Daily repetitive transcranial magnetic stimulation (rTMS) improves mood in depression. Neuroreport. 1995;6(14):1853-6. [PubMed: 8547583].

17. Forogh B, Ahadi T, Nazari M, Sajadi S, Abdul Latif L, Akhavan Heja $\mathrm{SM}$, et al. The effect of repetitive transcranial magnetic stimulation postural stability after acute stroke: A clinical trial. Basic Cl $\mathrm{VF}$, yos
2017;8(5):405-11. doi: 10.18869/nirp.bcn.8.5.405. [PubMed: 29167727]. [PubMed Central: PMC5691172].

18. Jhanwar VG, Bishnoi RJ, Jhanwar MR. Utility of repetitive transcranial stimulation as an augmenting treatment method in treatmentresistant depression. Indian J Psychol Med. 2011;33(1):92-6. doi: 10.4103/0253-7176.85406. [PubMed: 22021964]. [PubMed Central: PMC3195166].

19. Langguth B, Eichhammer P, Zowe M, Landgrebe M, Binder H, Sand $\mathrm{P}$, et al. Modulating cerebello-thalamocortical pathways by neuronavigated cerebellar repetitive transcranial stimulation (rTMS). Neurophysiol Clin. 2008;38(5):289-95. doi: 10.1016/j.neucli.2008.08.003. [PubMed: 18940616].

20. Perez MA, Lungholt BK, Nielsen JB. Short-term a apta ns in spinal cord circuits evoked by repetitive trans anial I agn acs mulation: Possible underlying mechanisms. Exp B doi: 10.1007/s00221-004-2144-2. [PubMed-155. 273].

21. Quartarone A, Bagnato S, Rizzo V, M gante F, Sà 'angelo A, Battaglia $\mathrm{F}$, et al. Distinct changes $\mathrm{n}$ cor al and pinal excitability following high-frequency repet e to to human motor cortex. Exp Brain Res. 2005;1 1):114-_ doi: 10.1007/s00221-004-2052-5. [PubMed: 15578171].

22. Gilbert DL. Low an igh-frec cy repetitive transcranial magnetic stip ation for th treatment of spasticity. Dev Med Child Neurol. 2007; (7)... doi: 111//j.1469-8749.2007.00486.x. [PubMed: 17593117].

23. Galhardoni $~$ orreia GS, Araujo H, Yeng LT, Fernandes DT, Kaziyama $\mathrm{HH}$, et al. Rep itive transcranial magnetic stimulation in chronic ר: A review of the literature. Arch Phys Med Rehabil. 2015;96/4 Sup $_{\mathrm{r}}$ 'S156-72. doi:10.1016/j.apmr.2014.11.010. [PubMed: 25437106]. Li Y, Q Yuan M, Du T. Low-frequency repetitive transcranial magetic imulation for patients with aphasia after stoke: A metaanalysis. J Rehabil Med. 2015;47(8):675-81. doi: 10.2340/16501977-1988. [PubMed: 26181486]. 